Article

\title{
Development of Cerium-Doped Hydroxyapatite Coatings with Antimicrobial Properties for Biomedical Applications
}

Daniela Predoi ${ }^{1}$, Simona Liliana Iconaru ${ }^{1}$, Mihai Valentin Predoi ${ }^{2}$, Andreea Groza ${ }^{3}$, Sofia Gaiaschi ${ }^{4}$, Krzysztof Rokosz ${ }^{5}$ D , Steinar Raaen ${ }^{6} \mathbb{D}_{\text {, }}$, Catalin Constantin Negrila ${ }^{1} \mathbb{D}$, Alina-Mihaela Prodan ${ }^{7,8}$, Adrian Costescu ${ }^{9}$, Monica Luminita Badea ${ }^{10}$ and Patrick Chapon ${ }^{4, *}$

1 National Institute of Materials Physics, Atomistilor Street, No. 405A, P.O. Box MG 07, 077125 Magurele, Romania; dpredoi@gmail.com (D.P.); simonaiconaru@gmail.com (S.L.I.); catalin.negrila@infim.ro (C.C.N.)

2 Department of Mechanics, University Politehnica of Bucharest, BN 002, 313 Splaiul Independentei, Sector 6, 060042 Bucharest, Romania; predoi@gmail.com

3 Plasma and Radiation Physics, National Institute for Laser, 409 Atomistilor Street, P.O. Box MG 36, 077125 Magurele, Romania; andreeagroza75@gmail.com

4 HORIBA Jobin Yvon S.A.S., 6-18, Rue du Canal, 91165 Longjumeau CEDEX, France; sofia.gaiaschi@horiba.com

5 Division of Surface Electrochemistry \& Technology, Faculty of Mechanical Engineering, Koszalin University of Technology, Racławicka 15-17, PL 75-620 Koszalin, Poland; krzysztof.rokosz@tu.koszalin.pl

6 Department of Physics, Norwegian University of Science and Technology (NTNU), Realfagbygget E3-124 Høgskoleringen 5, 7491 Trondheim, Norway; steinar.raaen@ntnu.no

7 Department of General Surgery, Carol Davila University of Medicine and Pharmacy, 8 Eroii Sanitari, Sector 5, 050474 Bucharest, Romania; prodan1084@gmail.com

8 Emergency Hospital Floreasca Bucharest, 8 Calea Floreasca, 014461 Bucharest, Romania

9 Faculty of Exact Sciences \& Engineering, Hyperion University of Bucharest, 169 Calea Călărași, 030615 Bucharest, Romania; adrian.costescu@gmail.com

10 Faculty of Horticulture, University of Agronomic Sciences and Veterinary Medicine, 59 Marasti Blvd., 011464 Bucharest, Romania; monibadea78@gmail.com

* Correspondence: patrick.chapon@horiba.com

Received: 1 May 2020; Accepted: 25 May 2020; Published: 28 May 2020

Abstract: Antibacterial cerium-doped hydroxyapatite (Ce-HAp) layers have been researched sparingly in recent years. The Ce-HAp powder, $\mathrm{Ca}_{10-\mathrm{x}} \mathrm{Ce}_{\mathrm{x}}\left(\mathrm{PO}_{4}\right)_{6}\left(\mathrm{OH}_{2}\right.$ with $\mathrm{x}_{\mathrm{Ce}}=0.05$, was obtained by an adapted chemical co-precipitation method at room temperature. The target was prepared using the Ce-HAp $\left(x_{C e}=0.05\right)$ powder sintered in air at $600{ }^{\circ} \mathrm{C}$. The coatings on the Ti substrate were generated in plasma using a radio frequency (RF) magnetron sputtering discharge in an Ar gas flow in a single run. To collect the most complete information regarding the antimicrobial activity of cerium-doped hydroxyapatite with $\mathrm{x}_{\mathrm{Ce}}=0.05$, (5Ce-HAp), antimicrobial studies were carried out both on the final suspensions and on the coated surfaces. The target was tested using ultrasound measurement, transmission electron microscopy (TEM), scanning electron microscopy (SEM), Fourier transform infrared spectroscopy (FTIR), glow-discharge optical emission spectroscopy (GDOES), and X-ray photoelectron spectroscopy (XPS). The present study exhibited for the first time results of the homogeneous coatings of hydroxyapatite doped with cerium using a radio frequency magnetron sputtering technique. In addition, this study highlighted for the first time the stability of the cerium-doped hydroxyapatite gels used in the creation of the coating. Ultrasound measurements on the concentrated suspension of 5Ce-HAp showed a good stability compared to double distilled, water which was chosen as the reference fluid. Particles with spherical shape were observed by both TEM and SEM analysis. The broadening of the IR bands in the IR spectrum of the 5Ce-HAp film in comparison with the IR spectrum of the precursor target indicate the formation of interlinked bonds 
into the layer bulk. XPS analysis revealed that the mixture of $\mathrm{Ce}^{3+}$ and $\mathrm{Ce}^{4+}$ ions in the hydroxyapatite (HAp) structure of the coatings could be due to the deposition process. The surface of 5Ce-HAp coatings was homogenous with particles having a spherical shape. A uniform distribution of all the constituent elements on the surface the 5Ce-HAp layer was revealed. The antimicrobial assays proved that both 5Ce-HAp suspensions and 5Ce-HAp coatings effectively inhibited the development of colony forming units (CFU) for all the tested microbial strains. Moreover, the antimicrobial assays emphasized that the 5Ce-HAp suspensions had a biocide effect against Escherichia coli (E. coli) and Candida albicans (C. albicans) microbial strains after $72 \mathrm{~h}$ of incubation.

Keywords: cerium; hydroxyapatite; ultrasound measurement; radio frequency magnetron sputtering; antimicrobial activity

\section{Introduction}

Currently, the most pressing problem from the health system is the emergence of multi-drug resistant microorganisms and the appearance of infections with these microorganisms [1-4]. The alarming and rapid increase in the appearance of drug-resistant microbial-related infections have forced researchers to focus their attention to the development of unconventional alternatives for treating microbial infections [1-3]. Over the years, various alternative options in the treatment of microbial infections, such as drug delivery systems, metal organic frameworks, nanoparticles, efflux pump inhibitors, light delivery systems, carbon based materials, peptides, etc., have been explored. Recently, an experimental approach used for a broad spectrum of biofilm-mediated diseases was intensively studied by photodynamic therapy (aPDT) for its particular applications in endodontics $[5,6]$. The most pronounced infections associated with multi-drug resistant microorganisms are those related to hospital equipment, improper wound dressings, and surgical instruments. One of the most studied materials for its outstanding antimicrobial properties is synthetic hydroxyapatite (HAp), having the chemical formula $\mathrm{Ca}_{10}\left(\mathrm{PO}_{4}\right)_{6}(\mathrm{OH})_{2}$, which is considered an essential inorganic material, very similar with human hard tissues that can be found in dentine, enamel, and bones $[7,8]$. In general, hydroxyapatite has been reported to be a material with excellent bioactivity, osteointegrity, biocompatibility, osteoinduction, and osteoconductivity properties and to have the capacity to interact directly with the human hard tissues and form bonds [9-11]. Due to its remarkable properties, HAp is used in a wide range of applications in the biomedical field for dentistry [11], tissue scaffolding [12], ossicular chain reconstruction [13], maxillofacial reconstruction [14], and as coating for metallic implants [15]. Over the years, the use of various metal ions such as $\mathrm{Ag}^{+}, \mathrm{Al}^{3+}, \mathrm{K}^{+}, \mathrm{Ce}^{3+}, \mathrm{Mg}^{2+}$, $\mathrm{Zn}^{2+}, \mathrm{La}^{3+}, \mathrm{Sr}^{2+}, \mathrm{Y}^{3+}$, and $\mathrm{In}^{3+}$ as dopants in the HAp lattice have been proposed to counteract the disadvantages of HAp, such as the lack of antibacterial activity, poor mechanical strength, etc. [16]. These ionic substitutions affect the crystallinity, lattice parameters, composition, and morphology of HAp, which lead to the development of an improved material with new properties such as chemical and mechanical stability, cytocompatibility, solubility, bioactivity, and antibacterial properties $[17,18]$. Cerium is a rare earth element that can accumulate in bones and has the ability to stimulate the metabolic activity of organisms [19]. There have been studies reporting on the wide use of Ce in medical applications in catheters, dentistry, and in the treatment of burn wounds $[16,20,21]$. Therefore, the development of cerium-doped hydroxyapatite will allow for the obtainment of a biocompatible and osteocoductive material with antibacterial activity. Moreover, the use of cerium-doped hydroxyapatite (Ce-HAp) in the development of biocompatible layers is a focus of current research. Over the years, numerous methods of layer deposition have been investigated to obtain homogenous, continuous, and stable coatings for different medical devices. Nanomaterials are considered to be on the leading edge of the field of nanotechnology. Their unique properties due to their size, shape, and surface area make these materials superior and indispensable in many areas of human activity. Particles with 
nanometric sizes are usually used for the development of biomaterials. Moreover, they are suitable for molecular assembly and may be made up of inorganic or polymeric materials; surface chemistry is often employed for their functionalization in order to improve their biological properties. Several studies have shown the importance of nanomaterials and their use in biomedical applications [22-26].

The radio frequency (RF) magnetron sputtering technique represents one of the methods applied to deposit thin films of hydroxyapatite on metallic or polymeric substrates, such as dental or orthopedic implants, for biomedical applications [27-29]. The calcium phosphate-based coatings obtained by the magnetron sputtering method are dense, pure, uniform in thickness, and have good adhesion to the substrate [28]. Hydroxyapatite films deposited as interlayers between implants and the human body have proven their utility in the acceleration process of prosthesis osseointegration [27-29].

The doping of the hydroxyapatite layers with different biological active ions such as $\mathrm{Ag}, \mathrm{Sr}, \mathrm{Zn}, \mathrm{Mg}$, $\mathrm{Ti}$, or Ce is significant for biomedical applications [30]. At the same time, it is a hard task as the physical, chemical, and biological properties of the HAp structure can be changed during $\mathrm{Ca}^{2+} /$ ion substitution. For example, Ag is an antimicrobial agent with inhibitory activity against bacteria and fungi while $\mathrm{Sr}$ and $\mathrm{Zn}$ have important roles in bone formation and wound healing. Mg-doped hydroxyapatite can stimulate osteogenesis, enhancing resistance to mechanical stress. Ti is a biocompatible material that promotes cell growth. Cerium ions can improve metabolism and possess antibacterial properties [31].

The replacement of $\mathrm{Ca}^{2+}$ with different ions into the HAp-deposited layer structure was performed with RF magnetron sputtering discharges using two or three precursor targets [32], one being HAp and the other one containing doping elements in different deposition parameters and configurations.

In this paper, we report the results on the Ce-HAp coatings generated with RF magnetron sputtering discharge using Ce-HAp as the precursor target with a Ce concentration of $5 \%$. Ce-doped hydroxyapatite coatings were previously generated by spin coating technique [31], electrolysis [33], or biomimetic methods [34].

In our previous study on cerium-doped hydroxyapatite nanoparticles synthesized by the co-precipitation method, we showed that cerium-doped hydroxyapatite may be prepared by the co-precipitation method at low temperatures, and Ce ions can enter into the HAp structure by substitution with calcium ions [35,36]. The current study presents for the first time the results concerning the stability of cerium-doped hydroxyapatite particles in suspension and a comparative study of the antimicrobial properties between the 5Ce-HAp suspension and the obtained coatings. The results regarding the homogeneity of the surface coatings and the mixture of $\mathrm{Ce}^{3+}$ and $\mathrm{Ce}^{4+}$ ions in the HAp structure of the coatings are also revealed.

\section{Materials and Methods}

\subsection{Materials}

The synthesis of $\mathrm{Ca}_{10-\mathrm{x}} \mathrm{Ce}_{\mathrm{x}}\left(\mathrm{PO}_{4}\right)_{6}(\mathrm{OH})_{2}$ was performed using ammonium hydrogen phosphate, $\left(\mathrm{NH}_{4}\right)_{2} \mathrm{HPO}_{4}$ (Sigma Aldrich, St. Louis, MO, USA, $\geq 99.0 \%$ ), calcium nitrate tetrahydrate, $\mathrm{Ca}\left(\mathrm{NO}_{3}\right)_{2} \cdot{ }_{4} \mathrm{H}_{2} \mathrm{O}$ (Sigma Aldrich, St. Louis, MO, USA, $\geq 99.0 \%$ ), cerium nitrate hexahydrate, $\mathrm{Ce}\left(\mathrm{NO}_{3}\right)_{2} \cdot 6 \mathrm{H}_{2} \mathrm{O}$ (Alpha Aesar, Kandel, Germany, $99.97 \%$ purity), ammonium hydroxide, $\mathrm{NH}_{4} \mathrm{OH}$ (Sigma Aldrich, St. Louis, MO, USA, 25\% $\mathrm{NH}_{3}$ in $\mathrm{H}_{2} \mathrm{O}(\mathrm{T})$ ), ethanol absolute, and double distilled water.

\subsection{Cerium-Doped Hydroxyapatite (CeHAp)}

In order to obtain the cerium-doped hydroxyapatite nanoparticles solution, an adapted chemical co-precipitation method [29] was used. The synthesis of $\mathrm{Ca}_{10-\mathrm{x}} \mathrm{Ce}_{\mathrm{x}}\left(\mathrm{PO}_{4}\right)_{6}(\mathrm{OH})_{2}, \mathrm{x}_{\mathrm{Ce}}=0.05,5 \mathrm{Ce}-\mathrm{HAp}$, was performed at room temperature. The $(\mathrm{Ca}+\mathrm{Ce}) / \mathrm{P}$ molar ratio of 1.67 was established in order to obtain the stoichiometric hydroxyapatite $[37,38] . \mathrm{Ca}\left(\mathrm{NO}_{3}\right)_{2} \cdot 4 \mathrm{H}_{2} \mathrm{O}$ and $\mathrm{Ce}\left(\mathrm{NO}_{3}\right)_{2} \cdot 6 \mathrm{H}_{2} \mathrm{O}$ were dissolved in absolute ethanol and added in a beaker with a solution of $\left(\mathrm{NH}_{4}\right)_{2} \cdot \mathrm{HPO}_{4} \cdot \mathrm{NH} 4 \mathrm{OH}$ was adding throughout the synthesis process to keep the $\mathrm{pH}$ constant at 11 . The solution was centrifuged after stirring and redispersed in deionized water. The resulting 5Ce-HAp suspension was stirred for $24 \mathrm{~h}$ 
at $100{ }^{\circ} \mathrm{C}$. After stirring, the resulting $5 \mathrm{Ce}-\mathrm{HAp}$ suspension was centrifuged, and the precipitate was dried in the oven at $100^{\circ} \mathrm{C}$.

\subsection{Thin Layer of CeHAp}

The 5Ce-HAp coatings were generated in plasma by an RF magnetron sputtering discharge in an Ar gas flow in a single run, using an RF magnetron source of 2 inches in diameter (acquired from K.J. Lesker Company, East Sussex, UK) and a Ce-HAp sputtering target. By mechanically pressing a Ce-HAp powder in air for a few minutes, the sputtering target was obtained. A $50 \mathrm{~W}$ RF power was applied to the magnetron source, placed at distance of $8 \mathrm{~cm}$ from the grounded substrate holder. The Ar working pressure of $4 \times 10^{-3} \mathrm{mbarr}$ (base pressure $\sim 10^{-5} \mathrm{mbarr}$ ) and the $6 \mathrm{mln} / \mathrm{min}$ Ar gas flow were maintained for the entire deposition time of $3 \mathrm{~h}$. Details about the experimental set-up of the deposition chamber were presented in [39]. The temperature at the substrate holder was monitored during the deposition process using a thermocouple probe (acquired from K.J. Lesker Company). It varied from $125^{\circ} \mathrm{C}$ (after $1 \mathrm{~h}$ deposition time) up to $135^{\circ} \mathrm{C}$ (after $3 \mathrm{~h}$ deposition time). The resulting 5Ce-HAp coatings were heat treated in an oven at $700{ }^{\circ} \mathrm{C}$ for $4 \mathrm{~h}$.

\subsection{Characterization Methods}

For the evaluation of the suspensions' stability, ultrasound measurements were conducted. The suspension was analyzed using ultrasound pulses according to previous studies [40]. At a very exact interval (5.00 s), digital signals were recorded. As a reference fluid for signal processing, double-distilled water was used. The double-distilled water is considered the most stable suspension.

The 5Ce-HAp suspensions were investigated by transmission electron microscopy with the aid of a CM 20 (Philips-FEI, Hillsboro, OR, USA) transmission electron microscope equipped with a Lab6 filament operating at $200 \mathrm{kV}$.

Furthermore, the morphology of the 5Ce-HAp suspensions and coatings were also investigated by scanning electron microscopy (SEM) using a Hitachi S4500 instrument (Hitachi, Tokyo, Japan). The distribution of the elemental constituents was investigated by energy-dispersive $X$-ray spectroscopy (EDS) using an EDAX (Ametek EDAX Inc., Mahwah, NJ, USA). For the 3D representation of the images, Image J software (Image J 1.51j8, National Institutes of Health, Bethesda, MD, USA) was used [41].

Complementary information about the surface morphology of the 5Ce-HAp coatings was obtained by atomic force microscopy (AFM) analysis. The AFM investigations were realized using a NT-MDT NTEGRA Probe Nano Laboratory instrument (NT-MDT, Moscow, Russia). The images were acquired using the non-contact mode with the aid of a silicon NT-MDT NSG01 cantilever coated with a $35 \mathrm{~nm}$ gold layer, with a tetrahedral tip and a curvature radius of $35 \mathrm{~nm}$ and a height of $14-16 \mu \mathrm{m}$. The studies were performed at room temperature and the AFM micrographs were acquired on surface areas of $3 \times$ $3 \mu \mathrm{m}^{2}$. The data analysis was performed using Gwyddion 2.55 software [42].

Molecular structure analysis of 5Ce-HAp thin films was performed by FTIR-ATR spectroscopy using a Perkin Elmer SP-100 spectrometer (Waltham, MS, USA), in the $400-4000 \mathrm{~cm}^{-1}$ spectral range. Identification of the entire vibrational structure of $\mathrm{P}-\mathrm{O}$ bonds was carried out by curve fitting analyses of the 5Ce-HAp layers in the range of $500-700 \mathrm{~cm}^{-1}$ and $1000-200 \mathrm{~cm}^{-1}$. This process includes a baseline correction of the experimental infrared spectrum and a second-order derivative calculation for peak wavenumbers identification. A Lorentz-type profile curve was used for finding the peak positions. The nonlinear least-squares data-fitting algorithm of the calculation software generated the sum of Lorentz fitted curves by multiple iterations. The algorithm provides a valid convergent solution when the position of the fitted curves is set correctly. The theoretical fitted curves were analyzed. The IR deconvoluted curves procedure was previously reported in [43].

Depth profiling of the 5Ce-HAp coatings was performed using GDOES (Horiba Company, Longjumeau, France). The operation conditions of the GD Profiler were $650 \mathrm{~Pa}, 35 \mathrm{~W}$ RF power impulse mode at $1 \mathrm{kHz}$, and a duty cycle of 0.25 . 
The X-ray photoelectron spectroscopy (XPS) measurements on titanium samples were performed using a SES 2002 instrument (Scienta Omicron, Taunusstein, Germany) using a monochromatic Al $\mathrm{K}(\mathrm{alpha})(\mathrm{h} v=1486.6 \mathrm{eV}) \mathrm{X}$-ray source (Scienta Omicron, $18.7 \mathrm{~mA}, 13.02 \mathrm{kV})$. Scan analyses were carried out with an analysis area of $1 \mathrm{~mm} \times 3 \mathrm{~mm}$ and a pass energy of $500 \mathrm{eV}$ with the energy step $0.2 \mathrm{eV}$ and step time $200 \mathrm{~ms}$. The binding energy of the spectrometer was calibrated by the position of the Fermi level on a clean metallic sample. The power supplies were stable and of high accuracy. The experiments were carried out in an ultra-high-vacuum system with a base pressure of about $6 \times 10^{-8} \mathrm{~Pa}$. The XPS spectra were recorded in normal emission. For the XPS analyses, the CasaXPS 2.3.14 software (Shirley background type) [44] with the help of XPS tables $[45,46]$ were used. All the binding energy values presented in that paper were charge corrected to $\mathrm{C} 1 \mathrm{~s}$ at $284.8 \mathrm{eV}$.

\subsection{In Vitro Antimicrobial Activity}

The antimicrobial activities of the 5Ce-HAp suspensions and coatings were investigated using common reference microbial strains, gram-positive Staphylococcus aureus ATCC 25923, gram-negative Escherichia coli ATCC 25922, and fungal strain Candida albicans ATCC 90029. The experiments were carried out using standard inoculums of a known concentration of $5 \times 10^{6} \mathrm{CFU} / \mathrm{mL}$ (colony forming units per milliliter) for each microbial strain. For the antimicrobial assays, both 5Ce-HAp suspensions and coatings were incubated with $1.5 \mathrm{~mL}$ of $5 \times 10^{6} \mathrm{CFU} / \mathrm{mL}$ microbial suspension in phosphate buffered saline (PBS) in a petri dish for different time intervals. In order to assess the antimicrobial activity of the tested samples, the suspensions were collected after 24,48 , and $72 \mathrm{~h}$ of incubation and seeded on agar medium for $24 \mathrm{~h}$ at $37^{\circ} \mathrm{C}$. Afterwards, the number of $\mathrm{CFU} / \mathrm{mL}$ was determined for each of the contacts. The assays were done in triplicate, and the results were presented as mean $\pm \mathrm{SD}$.

\section{Results and Discussions}

For the most complete information regarding the antimicrobial activity of cerium-doped hydroxyapatite with $\mathrm{x}_{\mathrm{Ce}}=0.05$ (5Ce-HAp), antimicrobial studies were carried out on the final suspensions, on the pressed powder (target), and on the coated surfaces.

The stability studies of the final 5Ce-HAp suspension performed by ultrasound measurements showed good stability (Figure 1). The value of the stability parameter was $s=\frac{1}{A_{m}}\left|\frac{d A}{d t}\right|=9.8 \times 10^{-6}$ $\mathrm{s}^{-1}$ in which $A_{m}$ is the averaged amplitude of the signals. Moreover, the ultrasound studies showed that the particles tend to concentrate near the separation surface during the sedimentation process. This increased concentration especially affected the higher frequency $(8 \mathrm{MHz})$ components of the recorded signal, as shown in Figure 1a. The highest amplitude ratio of 0.83 for the frequency of 3 $\mathrm{MHz}$ and the lowest of 0.75 at $8 \mathrm{MHz}$ are presented in Figure 1a. All values are relative to those of the reference fluid in the same conditions. Before $t=420 \mathrm{~s}$, the amplitudes at all selected frequencies were slowly decreasing. After the separation, the surface descends in front of the transducers and these amplitudes tend to 1 , which is normal for a complete sedimentation. The attenuation dependency of frequency for both the 5Ce-HAp suspension and the reference fluid are presented in Figure 1b. As can be seen from the attenuation dependence of frequency, the 5Ce-HAp suspension had good stability compared to that of the reference fluid.

For the present samples, similar results have never been presented in the literature. However, a similar ultrasonic technique was used in "Measurement of attenuation and dispersion using an ultrasonic spectroscopy technique" [47] and "Ultrasonic wave propagation in colloidal suspensions and emulsions: a comparison of four models" [48]. More details are given in the classical textbook "Ultrasound for Characterizing Colloids" [49]. Compared with the last reference, we prefer to show the time variation of spectral components of the suspension, capturing the entire sedimentation process (Figure 1a). The first stage provides information about stability (we computed the slope in this region and a small slope indicates a good stability), the rapid variation towards the settled state is shown to confirm the convergence towards the properties of water, the reference fluid. Figure $1 \mathrm{~b}$ compares the sample with the reference fluid. Some authors show the attenuation in $\mathrm{dB} / \mathrm{cm} / \mathrm{MHz}$ but this can 
be more difficult to use in practice, where the relative attenuation in $\mathrm{dB}$ (or nepper in our case) must ensure the detectability of the signal passing through a certain distance in the sample. In addition, similar plots to the present manuscript were used in previous studies $[37,40]$.
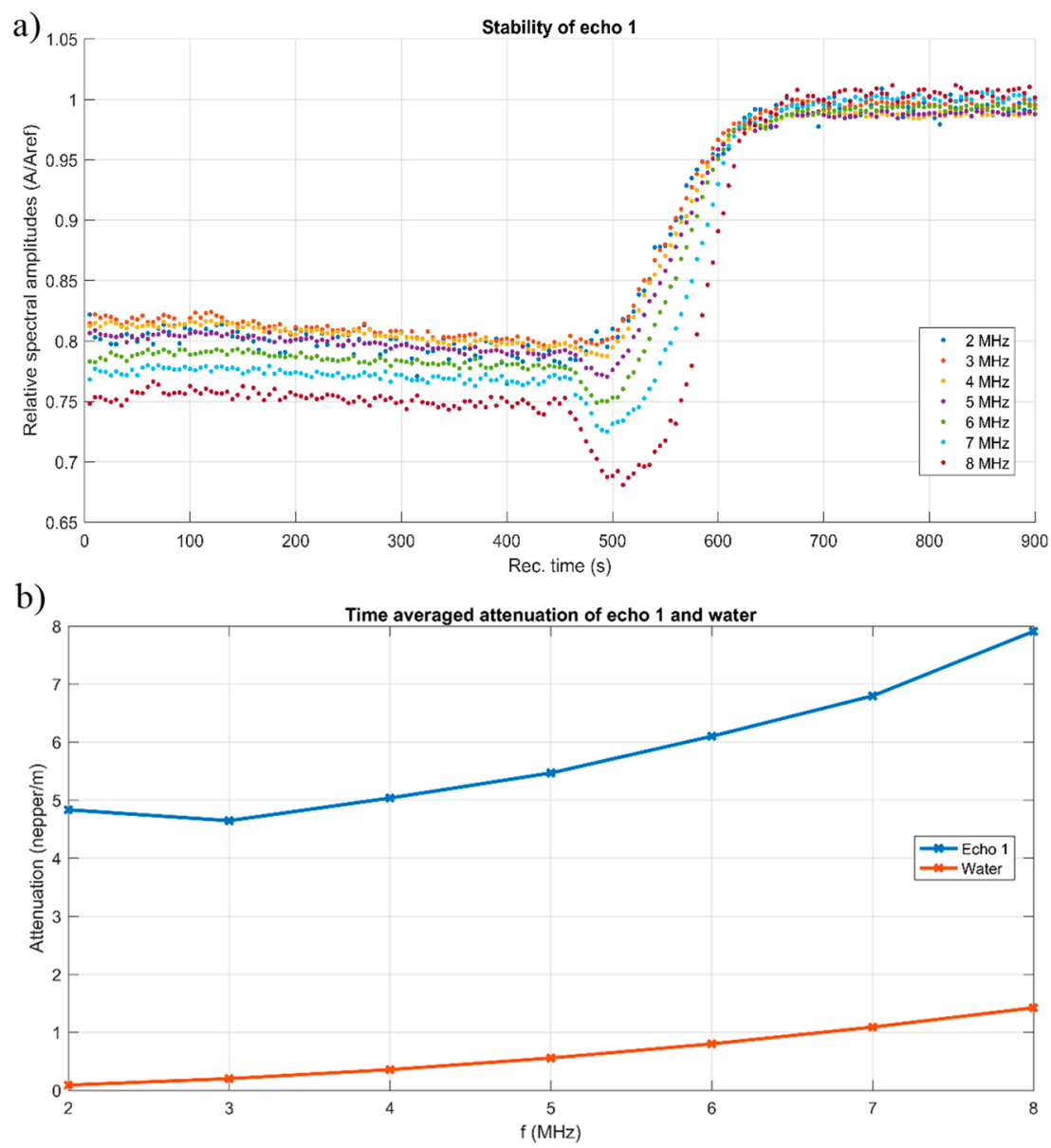

Figure 1. Spectral amplitudes relative variation vs. time, for the first echo (a) and attenuation vs. frequency for the first transmitted echo $(\mathbf{b})$.

TEM and SEM analyses of the 5Ce-HAp suspension are presented in Figure 2. The morphology of the 5Ce-HAp suspension evaluated by TEM analysis (Figure 2a) shows the particles with spherical shape. The SEM analysis of the 5Ce-HAp suspension (Figure $2 b$ ) also revealed particles with spherical shape. Both MET and SEM analyses showed that the 5Ce-HAp particles appear to be agglomerated. The agglomeration process cannot be prevented because the particles precipitated after the centrifugation of the suspension tend to become crowded during the drying process.

The $\mathrm{PO}_{4}{ }^{3-}$ groups specific to the HAp structure traditionally exhibit vibrational modes at $470 \mathrm{~cm}^{-1}$ $\left(v_{2}\right), 500-630 \mathrm{~cm}^{-1}\left(v_{4}\right), 960 \mathrm{~cm}^{-1}\left(v_{1}\right)$, and 1000-1100 $\mathrm{cm}^{-1}\left(v_{3}\right)$ [50,51]. Additionally, small IR bands due to $\mathrm{CO}_{3}{ }^{2-}$ groups or $\mathrm{OH}$ - groups at 1400 and $1630 \mathrm{~cm}^{-1}$ can also be observed.

The IR bands characteristic to the $\mathrm{PO}_{4}{ }^{3-}$ group in the HAp structure can be broadened or shifted by a few $\mathrm{cm}^{-1}$ to lower or higher frequencies as a function of the HAp doping concentration or material type (bulk, nanoparticles, or films). In these cases, the curve fitting analysis of IR bands is essential for the understanding of molecular structure of the chemical compound.

In Figure 3, the IR spectrum of the 5Ce-HAp sputtering target (Figure 3a) in comparison with that of the 5Ce-HAp films (Figure 3b) generated by the RF magnetron sputtering technique, together with the fitted curves, are presented. The 474 (O-P-O bonding mode), 960 (P-O symmetric stretching), and 1035 and $1101 \mathrm{~cm}^{-1}$ (P-O asymmetric stretching) IR bands present in the IR spectrum of the 5Ce-HAp coating can be attributed to the internal vibrations in the $\mathrm{PO}_{4}{ }^{3-}$ groups in the apatitic 
structure [32]. In the IR spectrum of the 5Ce-HAp target precursor (Figure 3a), these IR bands are identified at 470 (O-P-O bonding mode), 960 (P-O symmetric stretching), and 1023 and $1090 \mathrm{~cm}^{-1}$ (P-O asymmetric stretching) [5,32].

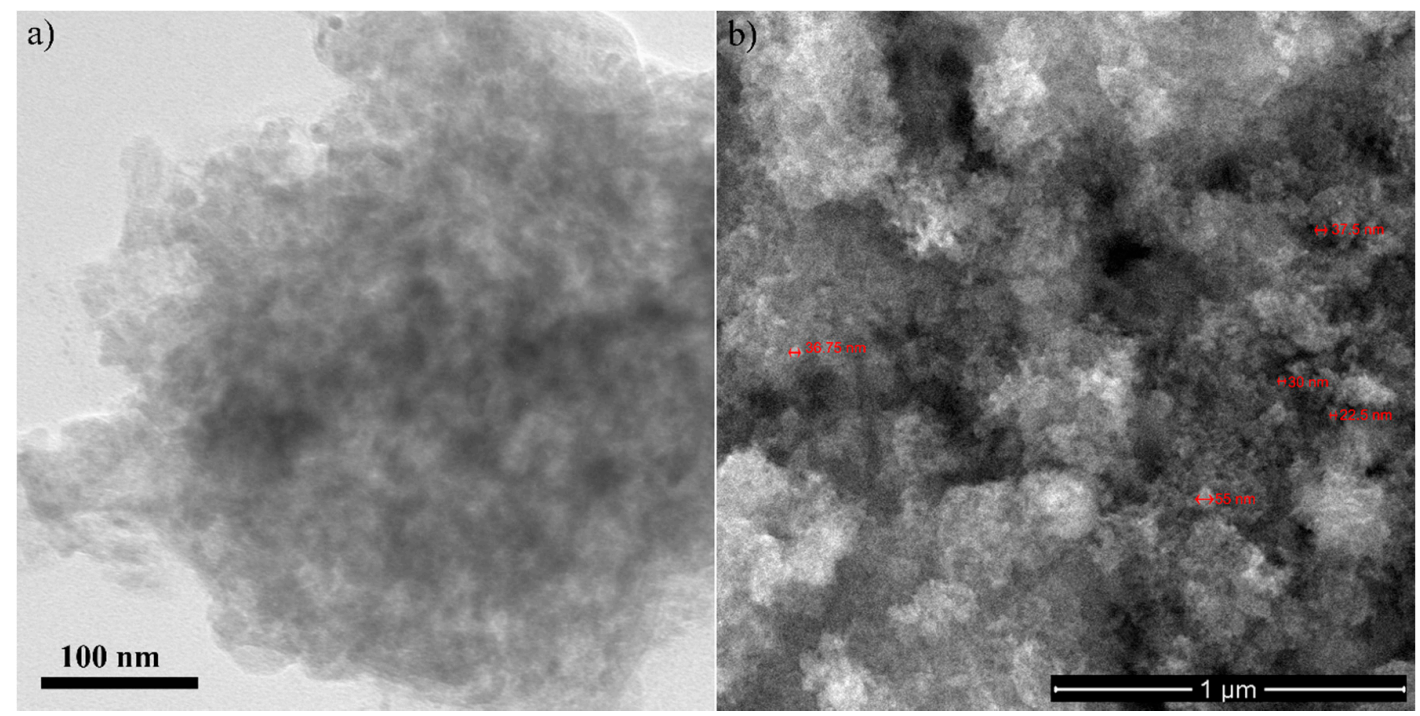

Figure 2. TEM analysis (a) and SEM image (b) of the 5Ce-HAp suspension. (Ce-HAp agglomerates are depicted in red). 5Ce-HAp: cerium-doped hydroxyapatite (Ce-HAp) with $\mathrm{x}_{\mathrm{Ce}}=0.05$.
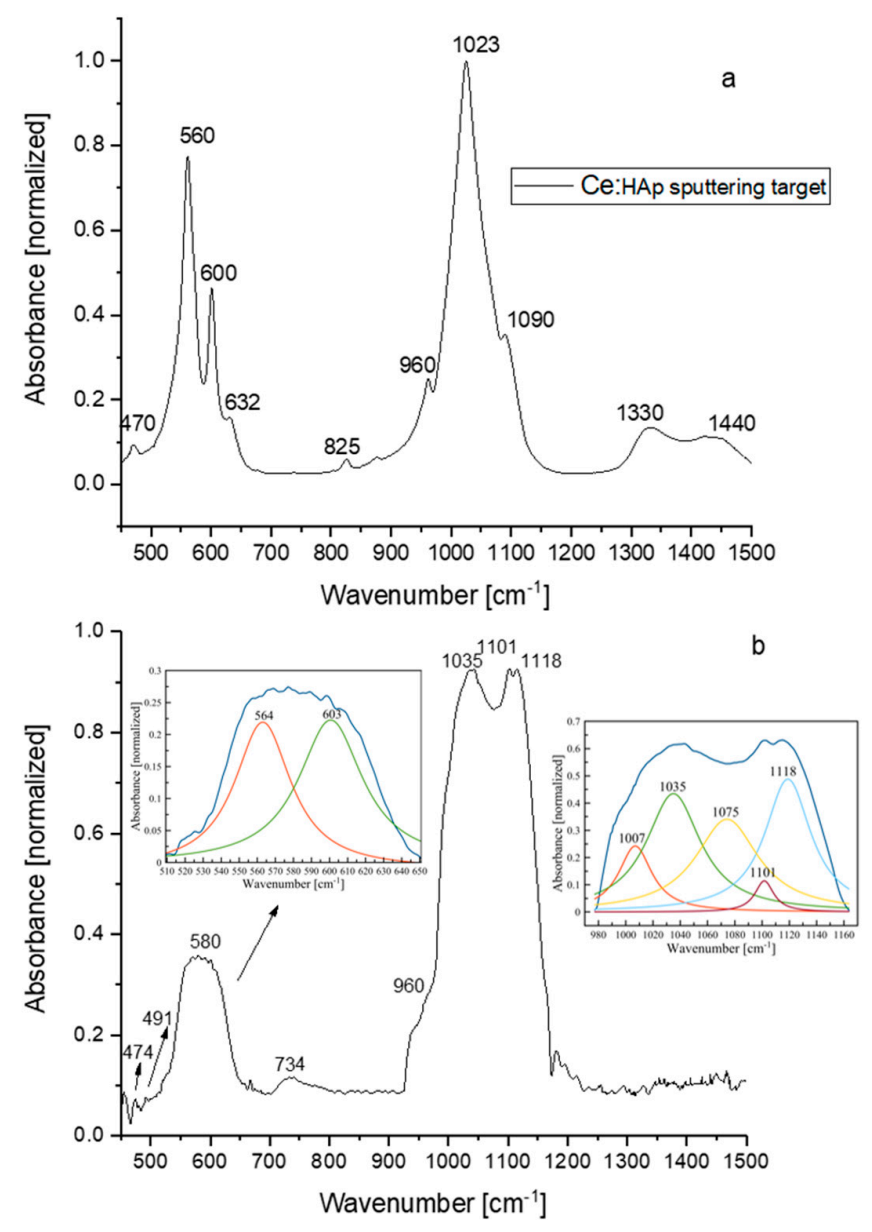

Figure 3. FTIR spectrum of (a) the 5Ce-HAp target and (b) the 5Ce-HAp coating deposited on the Si substrate. 
The deconvolution of the IR bands centered at $\sim 580$ and $\sim 1070 \mathrm{~cm}^{-1}$ also revealed the apatitic structure of the deposited layers (Figure 3b). The deconvoluted curves from 564 and $603 \mathrm{~cm}^{-1}$ belong to $\mathrm{P}-\mathrm{O}$ internal vibrations $\left(\mathrm{O}-\mathrm{P}-\mathrm{O}\right.$ bending mode $\left.v_{4}\right)$ in $\mathrm{PO}_{4}{ }^{3-}$, while the 1035,1075 , and $1101 \mathrm{~cm}^{-1}$ bands are characteristic of the symmetric and asymmetric stretching vibrations of $\mathrm{P}-\mathrm{O}$ in $\mathrm{PO}_{4}{ }^{3-}$ [5]. The bands from 1007 and $1118 \mathrm{~cm}^{-1}$ were previously associated to the vibrations of $\mathrm{P}-\mathrm{O}$ bonds in the non-apatitic phosphate structure [32]. In the spectrum of the 5Ce-HAp target (Figure 3a), the O-P-O bending vibrations manifested an absorption band at $560 \mathrm{~cm}^{-1}$. The broadening of the IR bands from $500-700 \mathrm{~cm}^{-1}$ and $900-1200 \mathrm{~cm}^{-1}$ in the IR spectrum of the 5Ce-HAp film in comparison with the IR spectrum of the precursor target indicate the formation of interlinked bonds in the layer bulk.

The 491 and $734 \mathrm{~cm}^{-1}$ bands could suggest the formation in the film of $\mathrm{CeO}_{2}$ and $\mathrm{P}_{2} \mathrm{O}_{7}{ }^{4-}$ groups, respectively, during the deposition process. The formation of $\mathrm{CeO}_{2}$ in the layer is possible, as during the deposition process, substitutions of $\mathrm{Ce}^{3+}$ and $\mathrm{Ce}^{4+}$ in the HAp structure [5] can occur. The substitution of $\left[\mathrm{Ce}^{3+} / \mathrm{Ce}^{4+}\right]$ for $\mathrm{Ca}^{2+}$ was correlated with the weakening of the IR bands, characteristic to O-H vibrations [5]. For balancing the charges in HAp, the $\mathrm{OH}$ are transformed to $\mathrm{O}^{2-}$. In Figure $3 \mathrm{~b}$ the presence of the IR bands specific to $\mathrm{CeO}_{2}$ (where cerium is bonded as $\mathrm{Ce}^{4+}$ ) and the absence of $630 \mathrm{~cm}^{-1}$ water molecules in the IR band are in agreement with the interpretations presented in [5]. The formation of the $\mathrm{P}_{2} \mathrm{O}_{7}{ }^{4-}$ group can be explain by the conversion of $\mathrm{HPO}_{4}{ }^{2-}$ in the deposition plasma [32].

The elemental depth profiling characterization of the 5Ce-HAp coatings was performed by GDOES. With this technique, the distribution of each element contained in a layer is given from its surface until the substrate interface. Each element depth profile curve is given as a function of sputtering time of the analyzed sample area (usually $4 \mathrm{~mm}$ of diameter surface).

Depth profiling investigation of the 5Ce-HAp sample deposited on the Si substrate by the magnetron sputtering technique exhibited distribution of $\mathrm{Ca}, \mathrm{P}, \mathrm{O}, \mathrm{H}, \mathrm{C}$, and $\mathrm{Ce}$ atoms into the coating. The time dependence of the depth profile curve of Si pointed out, in addition to the layer/substrate interface, the connection between the elements contained in the deposited layer. Thus, it can be observed in Figure 4 that the depth profiles of $\mathrm{Ca}, \mathrm{P}, \mathrm{O}$, and Ce have similar behavior. At the interface between the Ce-HAp coating and the Si substrate some peaks can be observed in the case of $\mathrm{Ca}, \mathrm{P}$, and Ce curves as an indication of their diffusion/implantation into the substrate. As these peaks have the same position on $\mathrm{x}$-axis, it is possible indicate the links between these elements in the Si substrate. There are no such peaks in the case of the other elements contained in the layer.

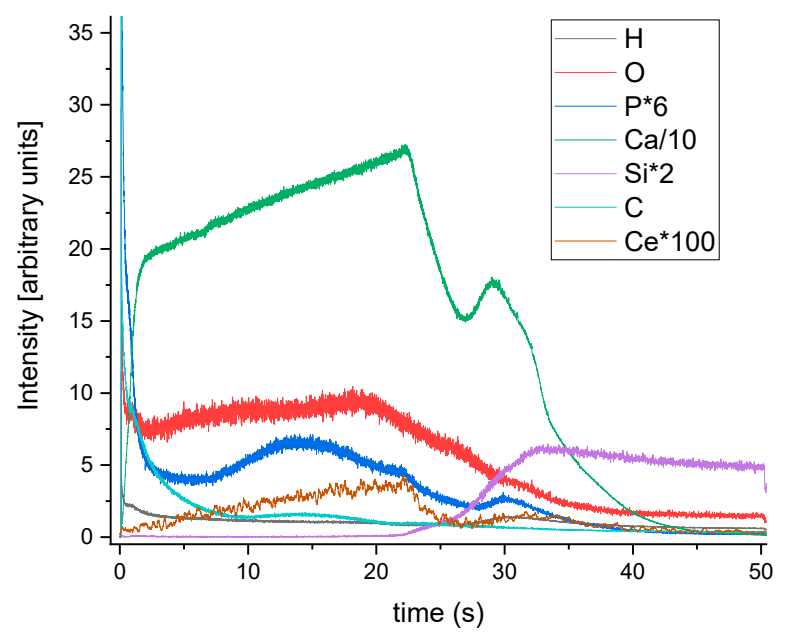

Figure 4. Elemental depth profiles of the 5Ce-HAp thin film deposited by radio frequency (RF) magnetron sputtering discharge on the Si substrate. 
In order to study the surface chemical state of cerium-doped hydroxyapatite and the evidence of successful doping of the HAp lattice with cerium ions, XPS analyses were conducted. On the other hand, XPS analysis was used to determine the oxidation state of Ce ions in the 5Ce-HAp sample. Thus, Figure 5 shows the XPS spectra of the 5Ce-HAp coated before etching (a) and after etching (b) for the binding energy $(\mathrm{BE})$ range of $0-1100 \mathrm{eV}$, calibrated with $\mathrm{C}$ 1s (before etching $289.5 \mathrm{eV}$, after etching $291.8 \mathrm{eV}$ ) as the reference. In the spectra of the 5Ce-HAp before and after etching, it can be clearly seen that the presence of $\mathrm{Ca}(2 p), \mathrm{P}(2 p), \mathrm{O}(1 s)$, and Ce (3d) with the BE of 340-350, 133, 351, and 880-930 eV was detected [52]. The main peaks assigned to the binding energies of $\mathrm{Ca} 2 \mathrm{p}, \mathrm{O} 1 \mathrm{~s}, \mathrm{P} 2 \mathrm{p}$, and $\mathrm{C}$ 1s are in good agreement with the previous studies of HAp [53]. The signal of the $C 1$ s element was due to the carbon used as a reference. The phase purity of HAp nanoparticles doped with Ce was confirmed by the absence of any peaks corresponding to the metal traces and other impurities in the survey spectrum of the 5Ce-HAp coatings. These results are in good agreement with the FTIR analysis of the coatings.
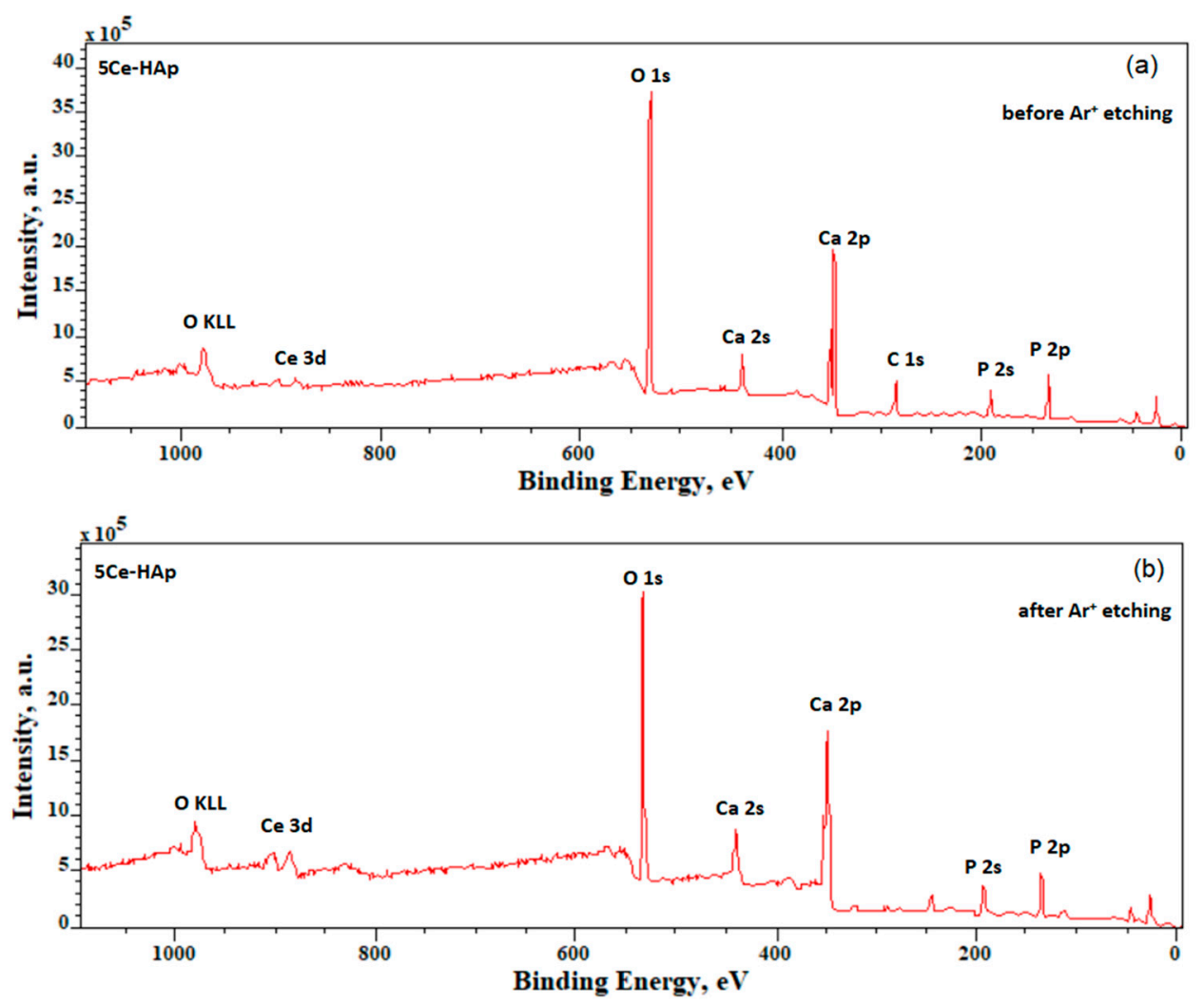

Figure 5. Spectra of the 5Ce-HAp coating before (a) and after (b) etching.

In Figure 6, the narrow scan spectrum of Ce (3d) before and after etching is exhibited. The spin orbit separation for $\mathrm{Ce} 3 \mathrm{~d}$ is about $18.5 \mathrm{eV}$. The aspect ratio between the $3 \mathrm{~d} 5 / 2$ and $3 \mathrm{~d} 3 / 2$ components was kept constant during the deconvolution. The individual features $(4 \mathrm{f} 2,4 \mathrm{f} 1$, and $4 \mathrm{f} 0)$ were varied during the fits. The amounts of $\mathrm{Ce}^{3+}$ and $\mathrm{Ce}^{4+}$ in the 5Ce-HAp layers were estimated from the area under the deconvoluted spectra. The results obtained after deconvolution of the Ce (3d) region of the 5Ce-HAp layers, before etching, showed that the percentage of $\mathrm{Ce}^{3+}$ ions was $79.7 \%$ and the percentage of $\mathrm{Ce}^{4+}$ ions was $20.3 \%$. On the other hand, after deconvolution of the $\mathrm{Ce}(3 \mathrm{~d})$ region of the $5 \mathrm{Ce}-\mathrm{HAp}$ layers, after etching, the percentage of $\mathrm{Ce}^{3+}$ ions was $78.5 \%$ while the percentage of $\mathrm{Ce}^{4+}$ ions was $21.5 \%$. As can be seen, the percentages of $\mathrm{Ce}^{3+}$ and $\mathrm{Ce}^{4+}$ ions calculated for the 5Ce-HAp layer before and after etching varied by $\sim 1 \%$ more or less. These results showed that the cerium ions that entered the crystal lattice of the hydroxyapatite through the substitution with calcium ions, existed as a mixture of $\mathrm{Ce}^{3+}$ and $\mathrm{Ce}^{4+}$ ions. The major valence state of $\mathrm{Ce}$ that replaced the $\mathrm{Ca}^{2+}$ ions was trivalent. This mixture of oxidation states in Ce-HAp could be caused by the high temperature 
treatment of the $5 \mathrm{Ce}-\mathrm{HAp}$ layers at $700{ }^{\circ} \mathrm{C}$ for $4 \mathrm{~h}$. Moreover, the mixture of $\mathrm{Ce}^{3+}$ and $\mathrm{Ce}^{4+}$ ions into the HAp structure may be due to the deposition process. The results of this study are in agreement with those previously presented by M. Yan et al. [54].
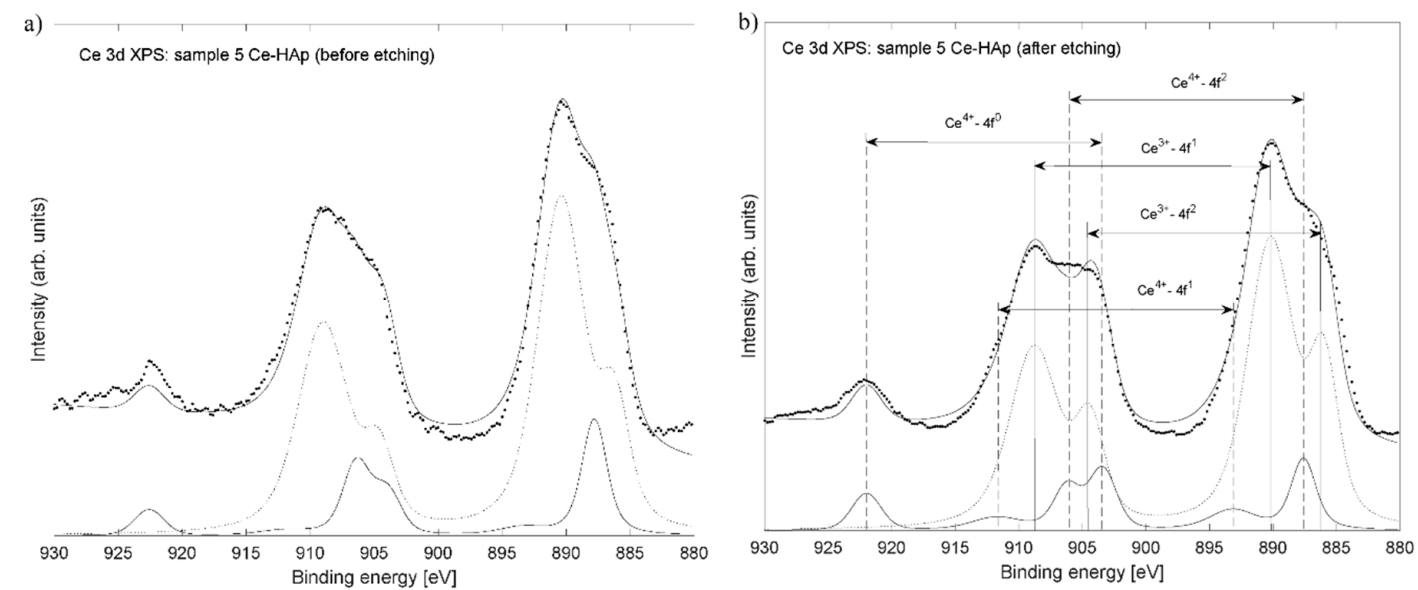

Figure 6. XPS Ce 3d regions of the 5Ce-HAp coating before (a) and after (b) etching. Upper spectra: Data and total fit after subtraction of a linear background. Lower spectra: Dotted line represents $\mathrm{Ce}^{3+}$ and solid line represents $\mathrm{Ce}^{4+}$. The various components of the $\mathrm{Ce}^{3+}$ and $\mathrm{Ce}^{4+}$ core levels corresponding to different $4 \mathrm{f}$-counts are shown in (b).

SEM micrographs and the EDS dot maps of different elements in the 5Ce-HAp coatings composite are shown in Figure 7. The surface was homogenous with particles having a spherical shape. Cracks in the layer were not observed. The EDS dot maps indicate that all constituent elements $(\mathrm{Ca}, \mathrm{P}, \mathrm{O}$, and $\mathrm{Ce})$ were uniformly distributed on the surface layer (Figure $7 \mathrm{~b}-\mathrm{e}$ ). The overlap of the constituent elements is also presented in Figure 7f.
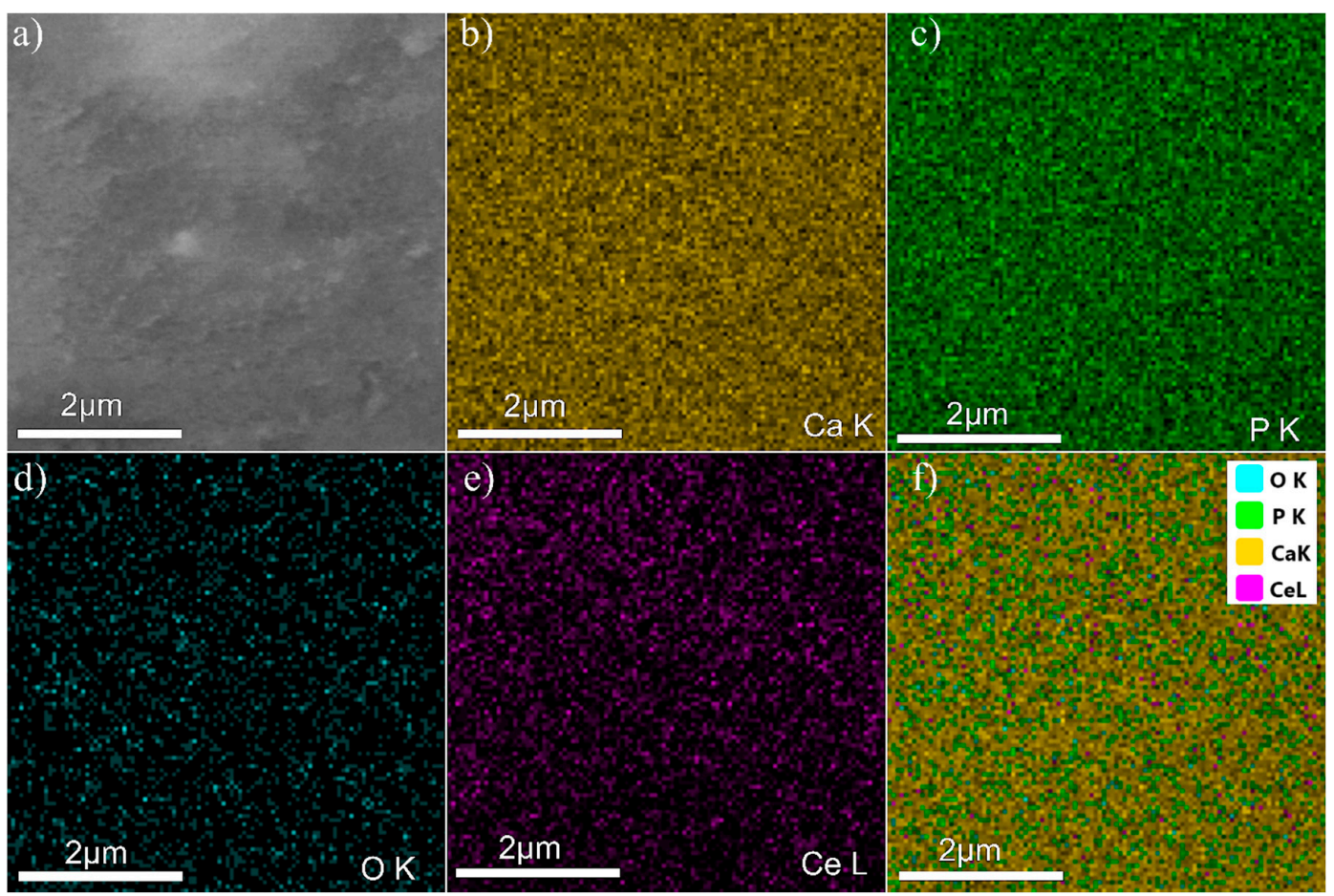

Figure 7. SEM surface morphology images of 5Ce-HAp (a). The element mapping of the prepared 5 Ce-HAp coating (b-e). The overlap of the constituent elements (f). 
In addition, the 2D conventional SEM image and its 3D representation obtained with the aid of Image J software (ImageJ 1.51j8, National Institutes of Health, Bethesda, MD, USA) [41] of the surface morphology of the 5Ce-HAp coatings is presented in Figure 8a,b. Both the 2D as well as the 3D representation of the SEM surface topography of the 5Ce-HAP coatings suggested the presence of a uniform deposition layer with no fissures or other imperfections.

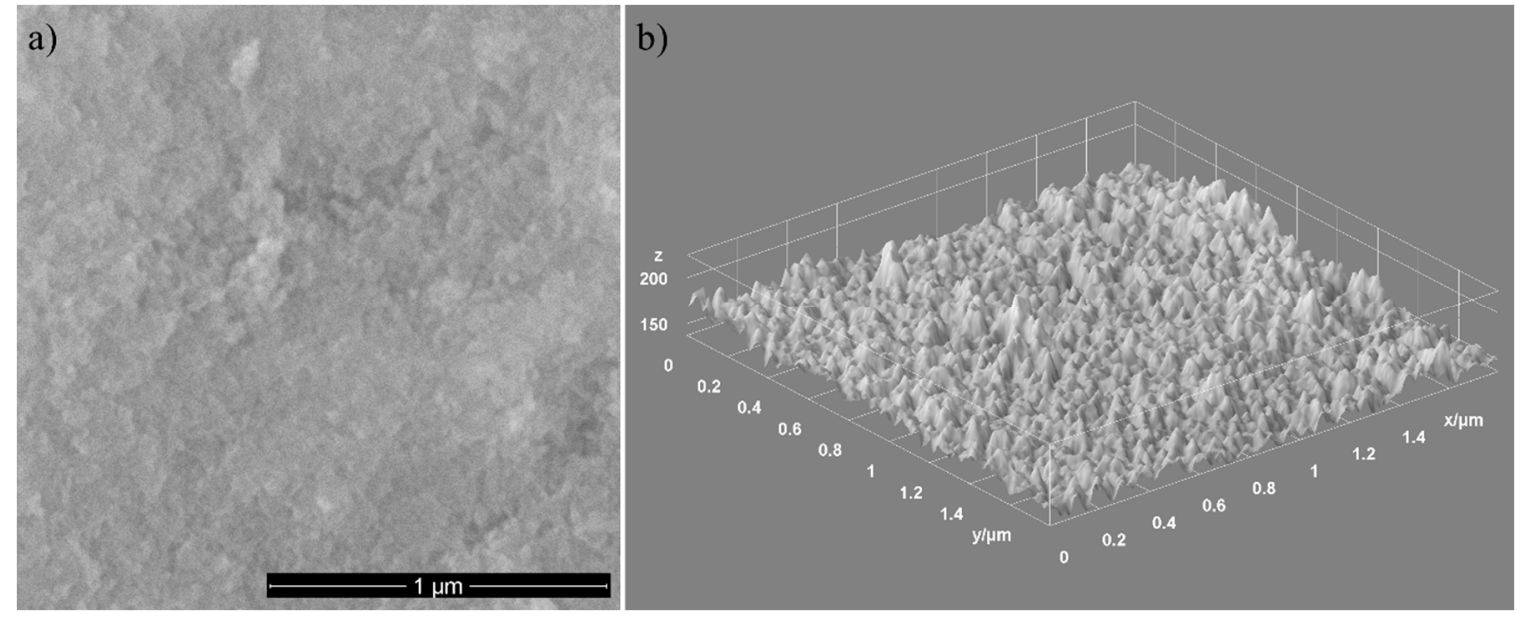

Figure 8. SEM image (a) and 3D representation of SEM image (b) of the 5Ce-Hap coatings.

The morphology of the 5Ce-HAp coating's surface was investigated using AFM studies. The surface topography of the 5Ce-HAp coatings is presented in Figure 9a. The 2D image of the surface morphology of the 5Ce-HAp coatings acquired by AFM analysis demonstrated that the 5Ce-HAp is a uniform and continuously deposited layer with no visible fissures and cracks. Furthermore, the 3D representation of the 2D topography depicted in Figure 9b of the 5Ce-HAp coatings also suggested the existence of a uniform and continuously deposited layer with no discontinuities. The results obtained using AFM analysis are in agreement with those of the SEM studies, which also revealed that the 5Ce-HAp coatings present a uniform and homogenous morphology.
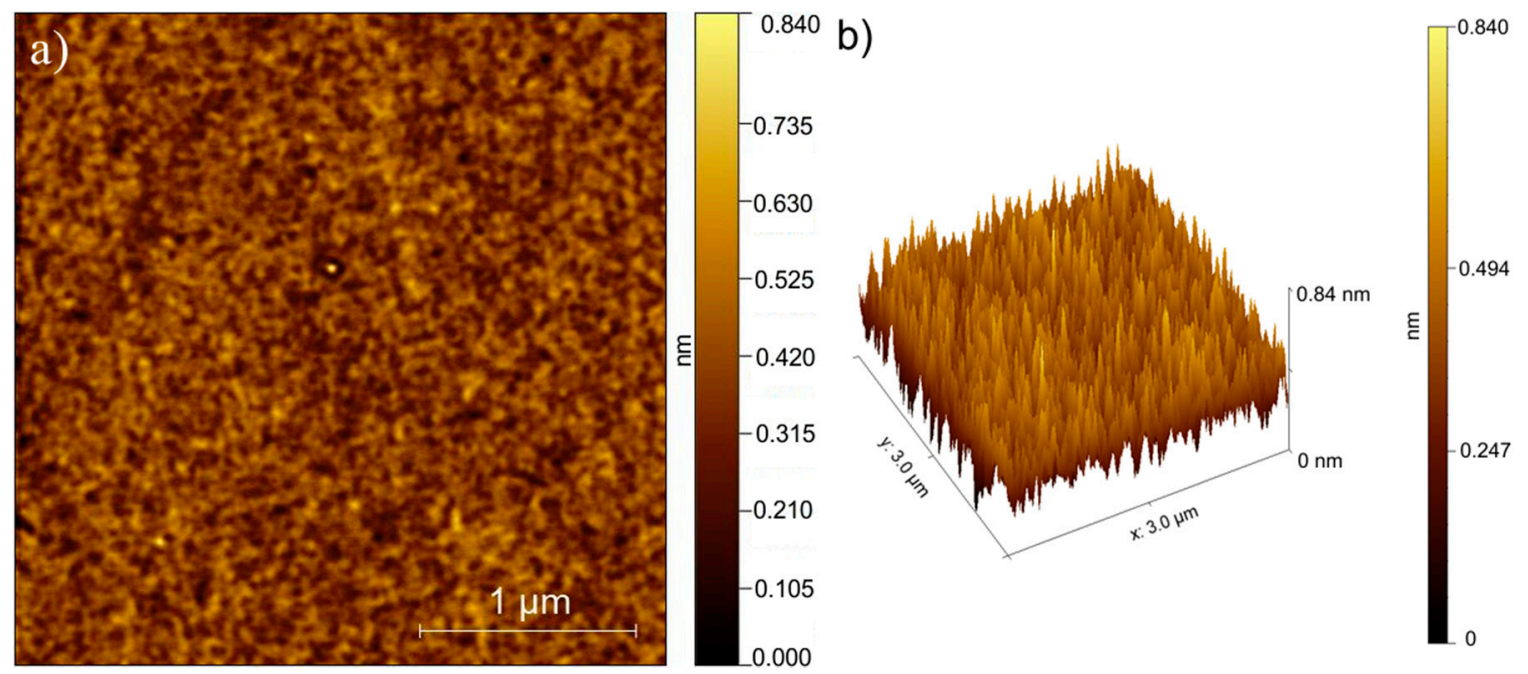

Figure 9. AFM topography image of the 5Ce-HAp coatings' surface presented in 2D (a) and 3D representation of the surface topography of the 5Ce-HAp coatings $(\mathbf{b})$.

In recent years, one of the main concerns of health care workers and researchers has been the emergence of drug resistant microbial strains. Therefore, considerable attention was paid to the development of new strategies for preventing and combating the infections caused by multi-drug 
resistant microbial strains. Two of the most prevalent emerging strains that have developed resistance to a wide range of antibiotics used as conventional antimicrobial treatments are gram-positive and gram-negative bacterial strains such as Staphylococcus aureus and Escherichia coli.

In this study, the antimicrobial activity of the 5Ce-HAp coatings, obtained from stable suspensions of 5Ce-HAp, as well as the antimicrobial efficiency of the 5Ce-HAp suspensions were investigated using gram-positive Staphylococcus aureus ATCC 25923, gram-negative Escherichia coli ATCC 25922, and fungal Candida albicans ATCC 90029. The antimicrobial activity of the samples against the tested microbial strains was investigated at various time intervals $(24,48$, and $72 \mathrm{~h}$ ). The antimicrobial efficiency of the samples was assessed by determining the CFU at different time intervals of incubation of the tested samples with standard solutions of the microbial strains. The results of the antimicrobial studies are presented in Figure 10.

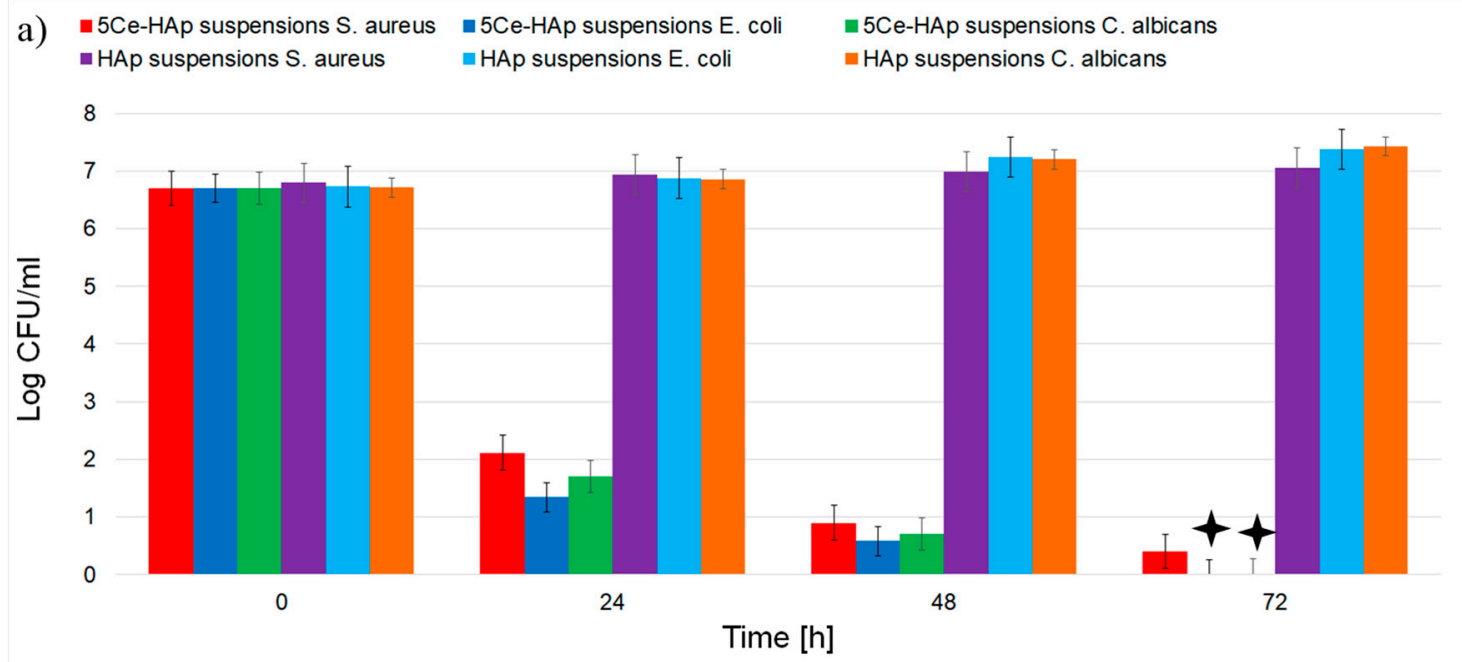

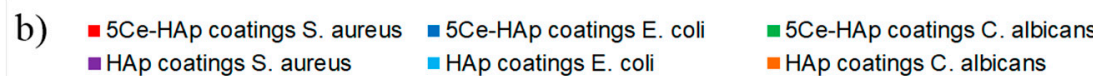

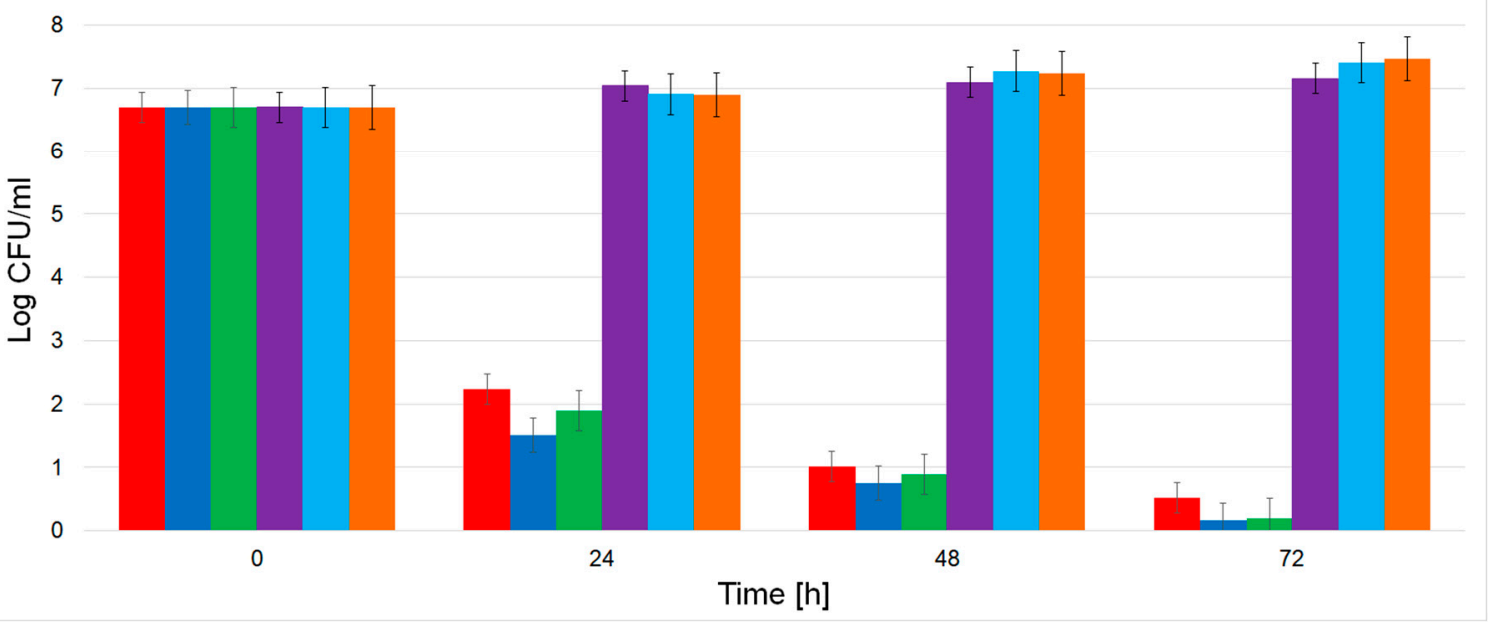

Figure 10. The graphical representation of the Log colony forming units (CFU)/mL as a function of time of exposure to the HAp and 5Ce-HAp suspensions (a) and HAp and 5Ce-HAp coatings (b).

The results obtained from the antimicrobial assays demonstrated that both 5Ce-HAp suspensions and 5Ce-HAp coatings effectively inhibited the development of CFU in the case of all tested microbial strains. Moreover, the antimicrobial efficacy of HAp suspensions and HAp coatings were also investigated. The results demonstrated that both HAp suspensions and HAp coatings aided the proliferation of the microbial cells and promoted their growth for all tested intervals and all investigated 
microbial strains. These results are in good agreement with previously reported studies regarding the lack of antimicrobial properties of hydroxyapatite $[37,55,56]$. Furthermore, the results also suggested that a biocidal effect was observed in the case of 5Ce-HAp suspensions against E. coli and C. albicans microbial strains after $72 \mathrm{~h}$ of incubation. Moreover, the results suggested that both in the case of 5Ce-HAp suspensions and 5Ce-HAp coatings the inhibitory effect against the development of microbial CFU was enhanced with the increase of the incubation time interval. In addition, the results of the antimicrobial assays suggested that the 5Ce-HAp suspensions were more efficient against the tested microbial strains than were 5Ce-HAp coatings for all tested microbial strains. Moreover, the data suggested that both 5Ce-HAp suspensions and 5Ce-HAp coatings inhibited the development of microbial cells after $24 \mathrm{~h}$ of incubation. These results are in good agreement with previous reported studies regarding the efficacy of cerium-doped hydroxyapatite in inhibiting microbial cells development $[35,57,58]$. The antimicrobial effects presented by both $5 \mathrm{Ce}-\mathrm{HAp}$ suspensions and 5Ce-HAp coatings were attributed to the presence of cerium ions in the lattice of the hydroxyapatite. These findings are also in good agreement with the existing studies [35,57,58]. Cerium is a rare earth element belonging to the lanthanides family and is present in the human body from the environment. These ions have the ability accumulate in bones and the liver. The biological effects of the cerium ions are not well known or documented, but recent studies have shown that cerium salts could stimulate some metabolic processes [59]. There are only a few reported studies regarding the antibacterial properties of cerium ions and their use in biomedical applications [60-62]. Both Lin et al. [62] and Ciobanu et al. [35] reported that the antibacterial properties of the samples was strongly influenced by the cerium ion concentration from the hydroxyapatite lattice. The mechanism involved in the antimicrobial properties of the cerium ions was attributed to the ability of producing reactive oxygen species, of inducing oxidative stress inflammation, or by inflicting direct damage to the microbial cells, but this is not a well-documented conclusion, and more complex studies should be performed in order to fully understand the mechanism involved in this $[35,57,58,63]$. Furthermore, in their study on the "Influence of thickness and coatings morphology in the antimicrobial performance of zinc oxide coatings", the authors revealed that when compared with the control, the thinner samples presented a less pronounced antibacterial activity than the thickest samples [64]. In addition, the study highlighted that the thickest coating showed a reduction in the number of bacterial cells [64]. Recent studies have also shown a correlation between the roughness of the coatings surface and their biological properties $[65,66]$. These studies confirm our results and emphasize that the antimicrobial activity of the investigated samples could be attributed not only to the chemical constituents of the coating but may also be influenced by the synergies developed between the chemical constituents of the Ce-HAp with the substrate, by the surface properties of the samples, and by the coatings thickness. In this context, the understanding of the mechanism of antimicrobial action of coatings could represent a first step in their optimal utilization as antimicrobial agents for biomedical applications.

The results obtained in this study are in good agreement with the few reports in the literature and suggest that both 5Ce-HAp suspensions and 5Ce-HAp coatings presented excellent antimicrobial properties against the most common and prevalent microbial strains often associated with hospital infections. The data also emphasized that the antimicrobial properties are strongly correlated with the incubation time for all tested microbial strains. Therefore, the results of this study suggest that both 5Ce-HAp suspensions and coatings could be successfully used in the development of novel antimicrobial agents for biomedical applications.

\section{Conclusions}

This paper presents the results of the antimicrobial properties of the 5Ce-HAp coatings generated in plasma by RF magnetron sputtering. For the first time, targets were obtained to achieve layers, taking into account the stability of the 5Ce-HAp suspensions. The surface of 5Ce-HAp coatings was homogenous with particles having a spherical shape, similar to the particles of the 5Ce-HAp suspension. The elemental mapping analysis of the 5Ce-HAp coatings revealed that the $\mathrm{Ca}, \mathrm{P}, \mathrm{O}$, 
and Ce chemical elements were uniformly distributed on the surface. The FTIR results were confirmed by XPS analysis. The FTIR results revealed the presence the $\mathrm{PO}_{4}{ }^{3-}$ groups specific to HAp structure. XPS analysis revealed a mixture of $\mathrm{Ce}^{3+}$ and $\mathrm{Ce}^{4+}$ ions in the HAp structure of $5 \mathrm{Ce}-\mathrm{HAp}$ coatings that may be due to the deposition process.

Furthermore, a comparative study of the antimicrobial properties of the 5Ce-HAp coatings and suspensions was performed. It has been shown that the layers generated from targets made from powders obtained by centrifugation of stable nanoparticle suspensions have antimicrobial properties similar to those of the suspensions. The antimicrobial assays of the 5Ce-HAp suspensions and 5Ce-HAp coatings demonstrated that they effectively inhibited the development of CFU for all tested microbial strains. Furthermore, the antimicrobial assays emphasized that the 5Ce-HAp suspensions had a biocidal effect against E. coli and C. albicans microbial strains after $72 \mathrm{~h}$ of incubation. In addition, the results also suggested that the antimicrobial effect of the suspensions and coatings are strongly correlated with the incubation time and also that the antimicrobial effects are attributed solely to the presence of cerium ions from the hydroxyapatite lattice. The antimicrobial assays of the HAp suspension and HAp coatings revealed that these materials presented a stimulating effect on the microbial cell development. These findings suggest that the 5Ce-HAp coatings obtained from 5Ce-HAp stable suspensions could be successfully used in the development of novel antimicrobial agents for biomedical applications, and future investigations should focus on the antimicrobial mechanisms of these types of materials.

Author Contributions: Conceptualization, D.P., M.V.P., P.C., and K.R.; Methodology, D.P., M.V.P., P.C., S.G., S.R., C.C.N., S.L.I., A.G., A.-M.P., and K.R.; Software, M.V.P.; Validation, D.P., M.V.P., P.C., S.G., S.R., C.C.N., S.L.I., A.G., A.-M.P., A.C., M.L.B., and K.R.; Formal Analysis, D.P., S.L.I., M.V.P., S.G., S.R., A.G., and K.R.; Investigation, D.P., M.V.P., P.C., S.G., S.R., C.C.N., S.L.I., A.G., A.-M.P., A.C., M.L.B., and K.R.; Resources, D.P., M.V.P., S.R., A.-M.P., and P.C.; Data Curation, D.P., S.L.I., and M.V.P.; Writing-Original Draft Preparation, D.P., M.V.P., S.L.I., A.G., S.R., and K.R.; Writing-Review and Editing, D.P., M.V.P., S.L.I., K.R., and A.G.; Visualization, D.P., M.V.P., P.C., S.G., S.R., C.C.N., S.L.I., A.G., A.-M.P., A.C., M.L.B., and K.R.; Supervision, D.P., M.V.P., K.R., S.G., and P.C.; Project Administration, D.P. and M.V.P.; Funding Acquisition, D.P. All authors have read and agreed to the published version of the manuscript.

Funding: This research was partially funded by the Romanian Ministry of Research and Innovation with the grant number and project number PN-III-P1-1.2-PCCDI-2017-0629/contract No. 43PCCDI/2018.

Conflicts of Interest: The authors declare no conflict of interest.

\section{References}

1. Darouiche, R.O. Treatment of infections associated with surgical implants. N. Engl. J. Med. 2004, 350, 1422-1429. [CrossRef] [PubMed]

2. Tiemersma, E.W.; Bronzwaers, S.L.; Lyytikäinen, O.; Degener, J.E.; Schrijnemakers, P.; Bruinsma, N.; Monen, J.; Witte, W.; Grundman, H. European Antimicrobial Resistance Surveillance System Participants. European antimicrobial resistance surveillance system participants: Methicillin-resistant Staphylococcus aureus in Europe. Emerg. Infect. Dis. 2004, 10, 1627-1633. [CrossRef] [PubMed]

3. Iconaru, S.L.; Prodan, A.M.; Turculet, C.S.; Beuran, M.; Ghita, R.V.; Costescu, A.; Groza, A.; Chifiriuc, M.C.; Chapon, P.; Gaiaschi, S.; et al. Enamel Based Composite Layers Deposited on Titanium Substrate with Antifungal Activity. J. Spectrosc. 2016, 2016, 1-13. [CrossRef]

4. Raita, M.S.; Iconaru, S.L.; Groza, A.; Cimpeanu, C.; Predoi, G.; Ghegoiu, L.; Badea, M.L.; Chifiriuc, M.C.; Marutescu, L.; Trusca, R.; et al. Multifunctional Hydroxyapatite Coated with Arthemisia absinthium Composites. Molecules 2020, 25, 413. [CrossRef]

5. Diogo, P.; Faustino, F.; Amparo, M.; Neves, P.M.S.; Graça, M.; Palma, P.J.; Santos, J.M. An Insight into Advanced Approaches for Photosensitizer Optimization in Endodontics-A Critical Review. J. Funct. Biomater. 2019, 10, 44. [CrossRef]

6. Swimberghe, R.C.D.; Coenye, T.; De Moor, R.J.G.; Meire, M.A. Biofilm model systems for root canal disinfection: A literature review. Int. Endod. J. 2018, 52, 604-628. [CrossRef]

7. Palmer, L.C.; Newcomb, C.J.; Kaltz, S.R.; Spoerke, E.D.; Stupp, S.I. Biomimetic systems for hydroxyapatite mineralization inspired by bone and enamel. Chem. Rev. 2008, 108, 4754-4783. [CrossRef] 
8. Phatai, P.; Futalan, C.M.; Utaraa, S.; Khemthong, P.; Kamonwannasit, S. Structural characterization of cerium-doped hydroxyapatite nanoparticles synthesized by an ultrasonic-assisted sol-gel technique. Results Phys. 2018, 10, 956-963. [CrossRef]

9. Bernards, M.T.; Qin, C.; Jiang, S. MC3T3-E1 cell adhesion to hydroxyapatite with adsorbed bone sialoprotein, bone osteopontin, and bovine serum albumin. Colloids Surf. B Biointerfaces 2008, 64, 236-247. [CrossRef]

10. Prodan, A.M.; Iconaru, S.L.; Predoi, M.V.; Predoi, D.; Motelica-Heino, M.; Turculet, C.S.; Beuran, M. Silver-Doped Hydroxyapatite Thin Layers Obtained by Sol-Gel Spin Coating Procedure. Coatings 2020, 10, 14. [CrossRef]

11. Suchanek, W.L.; Shuk, P.; Byrappa, K.; Riman, R.E.; TenHuisen, K.S.; Janas, V.F. Mechanochemical-hydrothermal synthesis of carbonated apatite powders at room temperature. Biomaterials 2002, 23, 699-710. [CrossRef]

12. Gopi, D.; Kanimozhi, K.; Bhuvaneshwari, N.; Indira, J.; Kavitha, L. Novel banana peel pectin mediated green route for the synthesis of hydroxyapatite nanoparticles and their spectral characterization. Spectrochim. Acta Part A Mol. Biomol. Spectrosc. 2014, 118, 589-597. [CrossRef] [PubMed]

13. Pasha, R.; Hill, S.L.; Burgio, D.L. Evaluation of hydroxyapatite ossicular chain prostheses. Otolaryngol. Head Neck Surg. 2000, 123, 425-429. [CrossRef] [PubMed]

14. Hench, L.L. Bioceramics. J. Am. Ceram. Soc. 1998, 81, 1705-1728. [CrossRef]

15. Fathi, M.H.; Hanifi, A. Evaluation and characterization of nanostructure hydroxyapatite powder prepared by simple sol-gel method. Mater. Lett. 2007, 61, 3978-3983. [CrossRef]

16. Supova, M. Substituted hydroxyapatites for biomedical applications: A review. Ceram. Int. 2015, 41, 9203-9231. [CrossRef]

17. Webster, T.J.; Ergun, C.; Doremus, R.H.; Bizios, R. Hydroxylapatite with substituted magnesium, zinc, cadmium and yttrium. II. Mechanisms of osteoblast adhesion. J. Biomed. Mater. Res. 2002, 59, 312-317. [CrossRef]

18. Turculet, C.S.; Prodan, A.M.; Negoi, I.; Teleanu, G.; Popa, M.; Andronescu, E.; Beuran, M.; Stanciu, G.A.; Hristu, R.; Badea, M.L.; et al. Preliminary Evaluation Of The Antifungal Activity Of Samarium Doped Hydroxyapatite Thin Films. Rom. Biotechnol. Lett. 2018, 23. [CrossRef]

19. Sahu, T.; Bisht, S.S.; Ranjan, D.K.; Kerkar, S. Nanoceria: Synthesis and biomedical applications. Curr. Nanosci. 2013, 9, 588-593. [CrossRef]

20. Yuntao, W.; Guohao, R.; Dongzhou, D.; Fan, Y.; Shangke, P. Study on the cerium oxidation state in a Lu0.8Sc0.2BO3 host. J. Mater. Chem. 2011, 21, 17805-17809.

21. Ouyang, Y.; Yushan, X.; Shaozao, T.; Qingshan, S.; Yiben, C. Structure and antibacterial activity of Ce3+ exchanged montmorillonites. J. Rare Earths 2009, 27, 858-863. [CrossRef]

22. Nakhjavani, M.; Nikkhah, V.; Sarafraz, M.M.; Shoja, S.; Sarafraz, M. Green synthesis of silver nanoparticles using green tea leaves: Experimental study on the morphological, rheological and antibacterial behaviour. Heat Mass Transfer 2017, 53, 3201-3209. [CrossRef]

23. Sarafraz, M.M.; Arya, A.; Nikkhah, V.; Hormozia, F. Thermal Performance and Viscosity of Biologically Produced Silver/Coconut Oil Nanofluids. Chem. Biochem. Eng. Q. 2016, 30, 489-500. [CrossRef]

24. Bahiraei, M.; Mazaheri, N.; Aliee, F.; Safaei, R. Thermo-hydraulic performance of a biological nanofluid containing graphene nanoplatelets within a tube enhanced with rotating twisted tape. Powder Technol. 2019, 355, 278-288. [CrossRef]

25. Salata, O.V. Applications of nanoparticles in biology and medicine. J. Nanobiotechnology 2004, 2, 1-6. [CrossRef]

26. Khan, I.; Saeed, K.; Khan, I. Nanoparticles: Properties, applications and toxicities. Arab. J. Chem. 2019, 12, 908-931. [CrossRef]

27. Surmenev, R.; Vladescu, A.; Surmeneva, M.; Ivanova, A.; Braic, M.; Grubova, I.; Cotrut, C.M. Radio Frequency Magnetron Sputter Deposition as a Tool for Surface Modification of Medical Implants. In Modern Technologies for Creating the Thin-Film Systems and Coatings, Edited by Nikolay Nikitenkov; InTech: London, UK, 2017; pp. 1-36.

28. Surmenev, R.A.; Surmeneva, M.A.; Grubova, I.Y.; Chernozem, R.V.; Krause, B.; Baumbach, T.; Epple, M. RF magnetron sputtering of a hydroxyapatite target: A comparison study on polytetrafluorethylene and titanium substrates. Appl. Surf. Sci. 2017, 414, 335-344. [CrossRef] 
29. López, E.O.; Mello, A.; Sendão, H.; Costa, L.T.; Rossi, A.L.; Ospina, R.O.; Borghi, F.F.; Silva Filho, J.G.; Rossi, A.M. Growth of crystalline hydroxyapatite thin films at room temperature by tuning the energy of the RF-magnetron sputtering plasma. ACS Appl. Mater. Interfaces 2013, 5, 9435-9445. [CrossRef]

30. Robinson, L.; Salma-Ancane, K.; Stipniece, L.; Meenan, B.J.; Boyd, A.R. The deposition of strontium and zinc Co-substituted hydroxyapatite coatings. J. Mater. Sci. Mater. Med. 2017, 28, 51. [CrossRef]

31. Yuan, Q.; Qin, C.; Wu, J.; Xu, A.; Zhang, Z.; Liao, J.; Lin, S.; Ren, P.; Zhang, P. Synthesis and characterization of Cerium-doped hydroxyapatite/polylactic acid composite coatings on metal substrates. Mater. Chem. Phys. 2016, 182, 365-371. [CrossRef]

32. Monsees, T.K.; Ak Azem, F.; Cotrut, C.M.; Braic, M.; Abdulgader, R.; Pana, I.; Birlik, I.; Kiss, A.; Booysen, R.; Vladescu, A. Biodegradable Ceramics Consisting of Hydroxyapatite for Orthopaedic Implants. Coatings 2017, 7, 184. [CrossRef]

33. Gopi, D.; Sathishkumar, S.; Karthika, A.; Kavitha, L. Development of $\mathrm{Ce}^{3+} / \mathrm{Eu}^{3+}$ Dual-Substituted Hydroxyapatite Coating on Surgical Grade Stainless Steel for Improved Antimicrobial and Bioactive Properties. Ind. Eng. Chem. Res. 2014, 53, 20145-20153. [CrossRef]

34. Ciobanu, G.; Harja, M. Cerium-doped hydroxyapatite/collagen coatings on titanium for bone implants. Ceram. Int. 2019, 4, 2852-2857. [CrossRef]

35. Ciobanu, C.S.; Popa, C.L.; Predoi, D. Cerium-doped hydroxyapatite nanoparticles synthesized by the co-precipitation method. J. Serb. Chem. Soc. 2016, 81, 433-446. [CrossRef]

36. Ciobanu, C.S.; Iconaru, S.L.; Massuyeau, F.; Constantin, L.V.; Costescu, A.; Predoi, D. Synthesis, structure, and luminescent properties of europium-doped hydroxyapatite nanocrystalline powders. J. Nanomater. 2012, 2012. [CrossRef]

37. Predoi, D.; Iconaru, S.L.; Predoi, M.V.; Motelica-Heino, M.; Guegan, R.; Buton, N. Evaluation of antibacterial activity of zinc-doped hydroxyapatite colloids and dispersion stability using ultrasounds. Nanomaterials 2019, 9, 515. [CrossRef]

38. Ciobanu, C.S.; Iconaru, S.L.; Popa, C.L.; Motelica-Heino, M.; Predoi, D. Evaluation of samarium doped hydroxyapatite, ceramics for medical application: Antimicrobial activity. J. Nanomater. 2015, 2015. [CrossRef]

39. Groza, A.; Dreghici, D.B.; Ganciu, M. Calcium Phosphate Layers Deposited on Thermal Sensitive Polymer Substrates in Radio Frequency Magnetron Plasma Discharge. Coatings 2019, 9, 709. [CrossRef]

40. Predoi, D.; Iconaru, S.L.; Predoi, M.V. Dextran-coated zinc-doped hydroxyapatite for biomedical applications. Polymers 2019, 11, 886. [CrossRef]

41. ImageJ. Available online: http://imagej.nih.gov/ij (accessed on 10 January 2018).

42. Gwyddion. Available online: http://gwyddion.net/ (accessed on 20 January 2020).

43. Groza, A.; Surmeian, A. Characterization of the oxides present in a polydimethylsiloxane layer obtained by polymerisation of its liquid precursor in corona discharge. J. Nanomater. 2015, 2015. [CrossRef]

44. CasaXPS: Processing Software for XPS, AES, SIMS and More. Available online: www.casaxps.com (accessed on 18 April 2020).

45. Biesinger, M.C.; Lau, L.W.M.; Gerson, A.R. Smart. Appl. Surf. Sci. 2010, 257, 887-898. [CrossRef]

46. Wagner, C.D.; Naumkin, A.V.; Kraut-Vass, A.; Allison, J.W.; Powell, C.J.; Rumble, J.R., Jr. NIST Standard Reference Database 20, Version 3.4. 2003. Available online: Srdata.nist.gov/xps (accessed on 15 April 2020).

47. Kline, R.A. Measurement of attenuation and dispersion using an ultrasonic spectroscopy technique. J. Acoust. Soc. Am. 1984, 76, 498-504. [CrossRef]

48. Tebbutt, J.S.; Challis, R.E. Ultrasonic wave propagation in colloidal suspensions and emulsions: A comparison of four models. Ultrasonics 1996, 34, 363-368. [CrossRef]

49. Dukhin, A.S.; Goetz, P.J. Ultrasound for Characterizing Colloids; Elsevier: Amsterdam, The Netherlands, 2002.

50. Jastrzębski, W.; Sitarz, M.; Rokita, M.; Bułat, K. Infrared spectroscopy of different phosphates structures. Spectrochim. Acta Part A Mol. Biomol. Spectrosc. 2011, 79, 722-727. [CrossRef]

51. Berzina-Cimdina, L.; Borodajenko, N. Research of Calcium Phosphates Using Fourier Transform Infrared Spectroscopy. In Infrared Spectroscopy - Materials Science, Engineering and Technology, Edited by Prof. Theophanides Theophile; InTech: London, UK, 2012.

52. Lu, H.B.; Campbell, C.T.; Graham, D.J.; Ratner, B.D. Surface characterization of hydroxyapatite and related calcium phosphates by XPS and TOF-SIMS. Anal. Chem. 2000, 72, 2886-2894. [CrossRef]

53. Kaciulis, S.; Mattogno, G.; Pandolfi, L.; Cavalli, M.; Gnappi, G.; Montenero, A. XPS study of apatite-based coatings prepared by sol-gel technique. Appl. Surf. Sci. 1999, 151, 1-5. [CrossRef] 
54. Yan, M.; Jianping, Y.; Zuoren, N. XPS study on the influence of calcinations to cerium ion valence. Spectrosc. Spectr. Anal. 2010, 1, 270-273.

55. Predoi, D.; Iconaru, S.L.; Buton, N.; Badea, M.L.; Marutescu, L. Antimicrobial Activity of New Materials Based on Lavender and Basil Essential Oils and Hydroxyapatite. Nanomaterials 2018, 8, 291. [CrossRef]

56. Predoi, D.; Iconaru, S.L.; Predoi, M.V.; Stan, G.E.; Buton, N. Synthesis, Characterization, and Antimicrobial Activity of Magnesium-Doped Hydroxyapatite Suspensions. Nanomaterials 2019, 9, 1295. [CrossRef]

57. Kolmas, J.; Groszyk, E.; Kwiatkowska-Różycka, D. Substituted Hydroxyapatites with Antibacterial Properties. BioMed Res. Int. 2014, 2014, 1-15. [CrossRef]

58. Yingguang, L.; Zhuoru, Y.; Jiang, C. Prepamtion, Chaiactelization and Antibacterial Property of Cerium Substituted Hydmxyapatite Nanoparticles. J. Rare Earths 2007, 25, 452-456.

59. Toxicological Review of Cerium Oxide and Cerium Compounds; US Environmental Protection Agency: Washington, DC, USA, 2009. Available online: http://www.epa.gov/iris/ (accessed on 20 April 2020).

60. Dai, G.; Yu, A.; Cai, X.; Shi, Q.; Ouyang, Y.; Tan, S. Synthesis, characterization and antimicrobial activity of zinc and cerium co-doped $\alpha$-zirconium phosphate. J. Rare Earths 2012, 30, 820-825. [CrossRef]

61. Wang, Y.Z.; Xue, X.X.; Yang, H. Preparation and characterization of zinc and cerium co-doped titania nano-materials with antibacterial activity. J. Inorg. Mater. 2013, 28, 117-122. [CrossRef]

62. Lin, Y.; Yang, Z.; Cheng, J. Preparation, characterizationand antibacterial property of cerium substituted hydroxyapatite nanoparticles. J. Rare Earths 2007, 25, 452-456. [CrossRef]

63. Hirst, S.M.; Karakoti, A.S.; Tyler, R.D.; Sriranganathan, N.; Seal, S.; Reilly, C.M. Anti-inflammatory Properties of Cerium Oxide Nanoparticles. Small 2009, 5, 2848-2856. [CrossRef]

64. Carvalho, P.; Sampaio, P.; Carneiro, J.O.; Vaz, C.; Espinós, J.P.; Teixeira, V. Influence of thickness and coatings morphology in the antimicrobial performance of zinc oxide coatings. Appl. Surf. Sci. 2014, 307, 548-557. [CrossRef]

65. Donlan, R.M. Biofilms: Microbial life on surfaces. Emerg. Infect. Dis. 2002, 8, 881-890. [CrossRef]

66. Katsikogianni, M.; Missirlis, Y.F. Concise review of mechanisms of bacterial adhesion to biomaterials and of techniques used in estimating bacteria-material interactions. Eur. Cells Mater. 2004, 8, 37-57. [CrossRef]

(C) 2020 by the authors. Licensee MDPI, Basel, Switzerland. This article is an open access article distributed under the terms and conditions of the Creative Commons Attribution (CC BY) license (http://creativecommons.org/licenses/by/4.0/). 